This item was submitted to Loughborough's Research Repository by the author.

Items in Figshare are protected by copyright, with all rights reserved, unless otherwise indicated.

\title{
Microstructural evolution of Ti6Al4V in ultrasonically assisted cutting: numerical modelling and experimental analysis
}

\section{PLEASE CITE THE PUBLISHED VERSION}

http://dx.doi.org/10.1016/j.ultras.2017.03.005

\section{PUBLISHER}

(c) Elsevier

\section{VERSION}

AM (Accepted Manuscript)

\section{PUBLISHER STATEMENT}

This work is made available according to the conditions of the Creative Commons Attribution-NonCommercialNoDerivatives 4.0 International (CC BY-NC-ND 4.0) licence. Full details of this licence are available at: https://creativecommons.org/licenses/by-nc-nd/4.0/

\section{LICENCE}

CC BY-NC-ND 4.0

\section{REPOSITORY RECORD}

Bai, Wei, Ronglei Sun, Jurgen Leopold, and Vadim Silberschmidt. 2017. "Microstructural Evolution of Ti6al4v in Ultrasonically Assisted Cutting: Numerical Modelling and Experimental Analysis". Loughborough University. https://hdl.handle.net/2134/25652. 


\title{
Microstructural evolution of Ti6Al4V in ultrasonically assisted cutting: Numerical modelling and experimental analysis
}

\author{
Wei Bai ${ }^{a}$, Ronglei Sun ${ }^{a, *}$, Jürgen Leopold ${ }^{b}$, Vadim V. Silberschmidt ${ }^{c}$ \\ a The State Key Lab of Digital Manufacturing Equipment and Technology, School of Mechanical Science and Engineering, Huazhong University of Science and Technology, \\ Wuhan 430074, China \\ b TBZ-PARIV GmbH, Chemnitz 09126, Germany \\ ${ }^{\mathrm{c}}$ Wolfson School of Mechanical, Electrical and Manufacturing Engineering, Loughborough University, Leicestershire LE11 $3 T U$, UK
}

\begin{abstract}
This paper aims to elucidate the effect of ultrasonically assisted cutting (UAC) on microstructure in a machined surface and a chip of Ti6Al4V alloy. To investigate microstructural evolution, a FE-based cutting model with an enhanced material formulation and temperature dependent material properties was developed. A Johnson-Mehl-Avrami-Kolmogorov (JMAK) model for the Ti6Al4V alloy was employed to simulate dynamic recrystallization and predict a resultant grain size. Due to a specific thermomechanical load in UAC, the distributions of strains, strain rates and temperatures in a workpiece in the machining process were investigated. In this study, five points under the machined surface and ten points under the unmachined one were tracked to compare the evolution of a grain size and its average magnitude in the alloy subjected to conventional cutting (CC) and UAC. Besides of numerical modelling and experimental studies for the resultant grain size were compared and additional validation using microhardness measurements were conducted. The results showed that the average grain size of the machined surface and the chip in case of UAC was larger and more uniform than that in case of CC. The study also presents discussions about the effect of a vibration amplitude, a feed rate and a cutting speed on the average grain size in machining of Ti6Al4V. The comparison between CC and UAC indicates that the change in average grain size in UAC was smaller than that in CC, thus demonstrating a lower level of damage in UAC.
\end{abstract}

\author{
Keywords: \\ Ultrasonically assisted cutting \\ Microstructure \\ Numerical modelling \\ Dynamic recrystallization \\ Low-damage process
}

\section{Introduction}

Ultrasonically assisted cutting (UAC) is a promising process with significant benefits over conventional cutting (CC) in terms of cutting force, cutting stability, tool wear, surface roughness, etc. (see a literature review by Brehl and Dow [1]). UAC was proven to be an efficient technique for improving the machinability of several aerospace materials such as titanium alloy [2] and nickel alloy [3].

It is well known that the microstructure of machined surface and subsurface strongly affect the performance of components in aerospace structures such as fatigue life, corrosion and wear resistance. In addition, microstructure of the formed chip is also important, especially for titanium alloys with segmented chips. Shivpuri et al. [4] stated that the segmentation phenomenon influenced chip morphology, cutting forces, chip-tool interface temperature, and dynamic behaviour of a cutting system. Therefore, more inves-

\footnotetext{
* Corresponding author.

E-mail address: ronglei@hust.edu.cn (R. Sun).
}

tigations are needed to reveal evolution and a final state of microstructure after the machining processes.

Accurate prediction of a microstructure induced by a machining process is a great challenge because of complex scenarios of its thermo-spatial evolution during a machining process affected by the cutting parameters, tool geometry and cutting conditions. Thus, the analytical or mechanistic model for microstructural evolution in machining is very hard to develop. A use of numerical simulations makes it possible to investigate microstructural changes in complex machining processes.

Numerical modelling of microstructure and its evolution in machining was of interest to many researchers. Simoneau et al. [5] investigated an effect of a grain size and orientation during microcutting of AISI 1045 steel. Incorporating microstructures into a finite-element (FE) cutting model yielded a more accurate representation of the workpiece material's stress-strain behaviour in a primary shear zone. Abouridouane et al. [6] proposed a 3D multiphase FE model for micro cutting of ferritic-pearlitic carbon steels to understand cutting, ploughing, tribological and heat transfer mechanisms at the microscale. Pu and Umbrello et al. [7] 
developed a FE model to simulate machining of an AZ31B Mg alloy under both dry and cryogenic conditions. A user subroutine was developed to predict the formation of machining-affected layers based on a dynamic-recrystallization mechanism. Rotella et al. [8] also used a user subroutine in their FE code to describe microstructural changes and to simulate the process of dynamic recrystallization. A procedure utilizing Zener-Hollomon and Hall-Petch equations was implemented to predict the evolution of grain size and surface hardness. Moussaoui et al. [9] investigated the effects of milling on microstructure and microhardness in Ti6Al4V.

Apparently, a microstructural model is essential to analyse the microstructure and a grain size in the cutting process. Several models exist for modelling the microstructural changes during thermo-mechanical processing, e.g. the Kocks-Mecking (KM) dislocation-density model [10], the Zener-Hollomon (ZH) model [8] and the Johnson-Mehl-Avrami-Kolmogorov (JMAK) recrystallization model [11]. The JMAK model is a widely used and established approach that is used here.

A specific character of UAC, with the cutting tool separating from a workpiece in each cycle of vibration, determines strain, strain rate, temperature, or microstructure different from those in CC. Until now, no systematic investigation of the microstructure in UAC as performed, except by Maurotto et al. [2]. They analysed the sub-surface layers of workpieces obtained with ultrasonically assisted turning (UAT) and its conventional counterpart. No visible changes were found in the UAT workpiece with this qualitative observation; however, microstructural changes of machined surfaces might be not obvious from such observations of metallographic structures. Thus, the investigation of microstructure evolution as a result of UAC is needed; so, both qualitative and quantitative comparisons are performed in this study.

The paper is organized as follows: In Section 2, a FE-based model of orthogonal cutting with an enhanced material constitutive model is presented and compared with two other models, with calculated cutting forces validated with experimental results. The JMAK microstructure model is used in Section 3 to predict dynamic recrystallization and a resultant grain size of a machined surface and a chip for UAC and CC. In Section 4, the average grain size of the surface machined with UAC and CC is compared and validated with optical microscopy; additionally, nanoindentation tests of the machined surface and chip were performed to validate the distribution of grain size. Besides, a series of simulations as performed to reveal the influence of cutting and vibration parameters on microstructure of workpieces subjected to CC and UAC. The paper ends with some concluding remarks in Section 5.

\section{Fe-based orthogonal cutting and validation}

In numerical simulations of processes involving irreversible deformation, a material constitutive model is required to calculate a flow stress. The Johnson-Cook $(\mathrm{J}-\mathrm{C})$ material model is widely used for this purpose in simulations of machining processes. It is defined as follows:

$\sigma=\left(A+B \varepsilon^{n}\right)\left[1+C \ln \frac{\dot{\varepsilon}}{\dot{\varepsilon}_{0}}\right]\left[1-\left(\frac{T-T_{r}}{T_{m}-T_{r}}\right)^{m}\right]$,

where $\sigma$ is the equivalent flow stress, $\varepsilon$ is the equivalent strain, $\dot{\varepsilon}$ is the equivalent strain rate, $\dot{\varepsilon}_{0}$ is the reference equivalent strain rate, $T$ is the workpiece temperature, $T_{r}$ is the room temperature, $T_{m}$ is the materials melting point. This model is defined by three terms, representing strain hardening, strain-rate sensitivity and thermal softening of material, respectively.

Unknown parameters $(A, B, C, n, m)$ of the $\mathrm{J}-\mathrm{C}$ material model can be obtained from experiments by using Split-Hopkinson pres- sure bar tests or cutting tests. The model parameters obtained by Lee and Lin [12] for Ti6Al4V (given in Table 1) have been broadly used; they were obtained at strain rates ranging from 500 to $3000 \mathrm{~s}^{-1}$ at temperatures up to $1100^{\circ} \mathrm{C}$ by means of a compressive Split-Hopkinson pressure bar technique; the maximum strain level was 0.35 . In machining process, strains can reach magnitudes of 5, even 10 [13]. The flow-stress curves of the J-C material model based on the parameters of Lee and Lin [12] are given in Fig. 1; with the maximum strain and strain rate extended to 5 and $10,000 \mathrm{~s}^{-1}$, respectively. The approach considers that the flow stress increases at high strains.

Sun and Guo [14] pointed out the difference between flow stresses in machining and compression tests. They observed that flow stress obtained at high strains was much lower than that measured in compression tests. Thus, J-C material model has some potential deficiencies at high strains.

In Finite-element software Deform-2D, a modified material model was developed as shown in Fig. 2, it includes the effect of flow softening at high strains.

A modified J-C material model was presented by Calamaz et al. [15]; it included flow softening at high strains and temperatures. Then Sima and Özel [16] added some parameters to the equation; the modified material flow stress is expressed as follows:

$$
\begin{aligned}
\sigma= & {\left[A+B \varepsilon^{n}\left(\frac{1}{\exp \left(\varepsilon^{a}\right)}\right)\right]\left[1+C \ln \frac{\dot{\varepsilon}}{\dot{\varepsilon}_{0}}\right]\left[1-\left(\frac{T-T_{r}}{T_{m}-T_{r}}\right)^{m}\right] } \\
& {\left[D+(1-D)\left[\tanh \left(\frac{1}{(\varepsilon+p)^{r}}\right)\right]^{s}\right] } \\
& D=1-\left(\frac{T}{T_{m}}\right)^{d}, p=\left(\frac{T}{T_{m}}\right)^{b}
\end{aligned}
$$

where $a, b, d, p, r, s$ are material constants. This approach modified a strain-hardening function of the J-C model by including flow softening at high strains, and the thermal softening function by including temperature-dependent flow softening. Therefore, this flow-stress equation takes into account the strain, strain rate, temperature and also the dynamic recovery and recrystallization mechanism.

Actually, the Calamaz-modified Johnson-Cook (Calamaz J-C) material model is based on the J-C model; it means that parameters $A, B, C, n, m$ of both models are obtained from SHPB experiments. Parameters $a, b, d, p, r, s$ of the Calamaz J-C material model could be chosen with numerical simulations.

Parameters of the Calamaz J-C material model for the Ti6Al4V alloy were identified by Özel et al. [17] and optimized in simulations (see Table 2). The flow-stress curves of this model are shown in Fig. 3.

According to Fig. 3, the approach introduces flow softening at high strains and high temperatures; the flow stress reaches the peak value and then decreases until strain reaches a magnitude of around two, after which a nearly constant stress is obtained.

In order to study microstructural evolution in conventional and ultrasonically assisted cutting, an accurate FE model is required. The updated Lagrangian formulation of software Deform-2D was used to achieve continuous remeshing to accommodate large deformations in the process zone. Three material models (J-C, Deform-2D and Calamaz J-C) for Ti6Al4V alloy were integrated into Deform-2D to simulate orthogonal cutting. A plane-strain thermomechanical coupled analysis was performed. The temperaturedependent material properties of Ti6Al4V alloy were introduced [17]; respective relationships for the modulus of elasticity $(E)$, coefficient of thermal expansion $(\alpha)$, thermal conductivity $(\lambda)$ and heat capacity $\left(c_{p}\right)$ are given in Table 3 for temperature $T$ in ${ }^{\circ} \mathrm{C}$.

In this paper, the serrated chip formation is simulated by employing a fracture criterion by Cockroft and Latham's [18]. It is expressed as:

$\int_{0}^{\bar{\varepsilon}_{f}} \sigma_{1} d \bar{\varepsilon}=D_{c}$ 
Table 1

Parameters of Johnson-Cook model for Ti6Al4V alloy.

\begin{tabular}{|c|c|c|c|c|c|}
\hline $\mathrm{J}-\mathrm{C}$ model & $A$ & $B$ & C & $n$ & $m$ \\
\hline Lee and Lin [12] & 724.7 & 683.1 & 0.035 & 0.47 & 1 \\
\hline
\end{tabular}

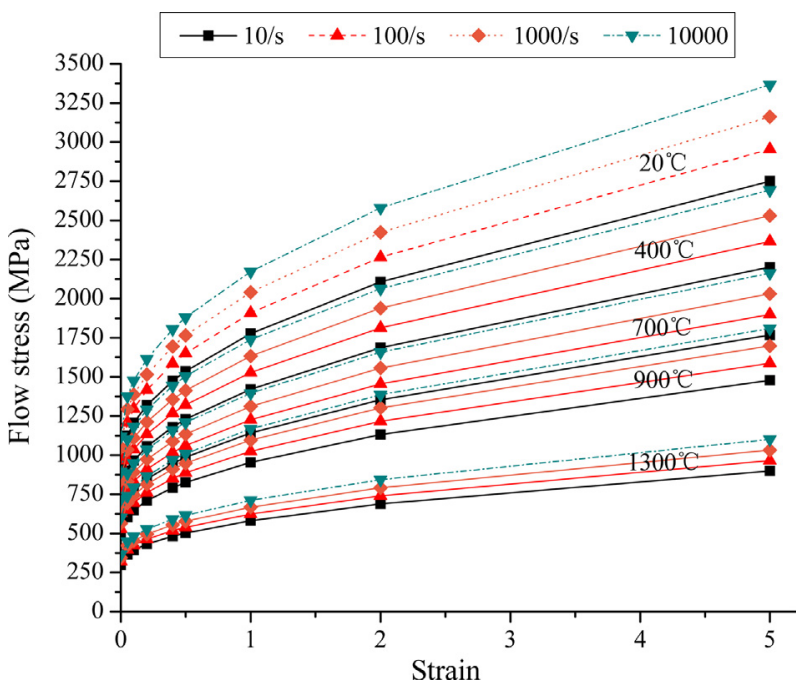

Fig. 1. Flow-stress curves of J-C material model (Lee and Lin [12]).

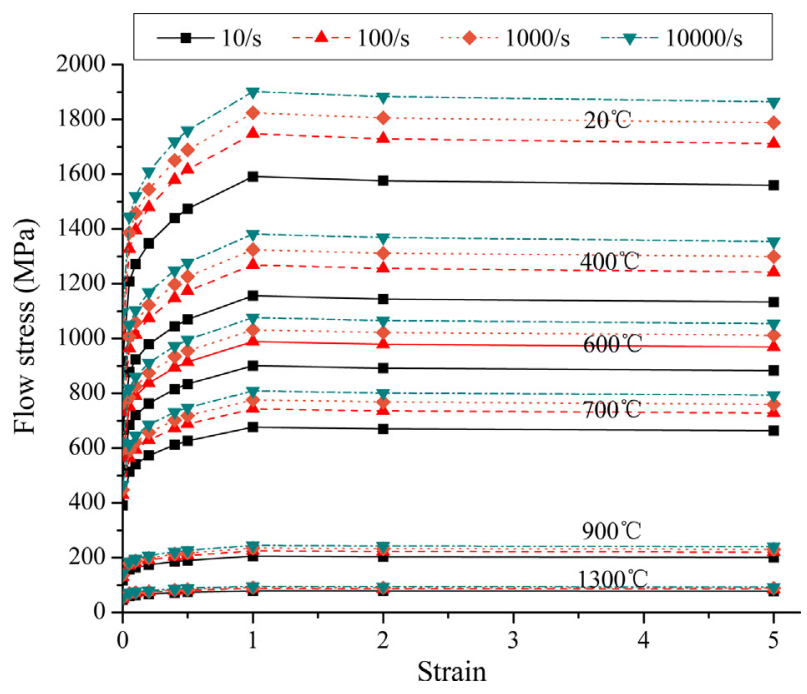

Fig. 2. Flow-stress curves of Deform-2D material model.

where $\bar{\varepsilon}_{f}$ is the effective strain, $\sigma_{1}$ is the major principal stress, $D_{c}$ is the material constant. This criterion relates the onset of fracture or chip segmentation to the integral of the major principal stress along the strain path reaching the critical value $D_{c}$; this value was chosen $245 \mathrm{MPa}$ in this paper [19].

To reflect the experiments, FE-based simulations of orthogonal cutting of Ti6Al4V alloy were performed using an uncoated tungsten carbide (WC) tool with sharp edges ( $5 \mu \mathrm{m}$ edge radius) at cutting speed of $121.9 \mathrm{~m} / \mathrm{min}$. The rake and relief angles of the tool

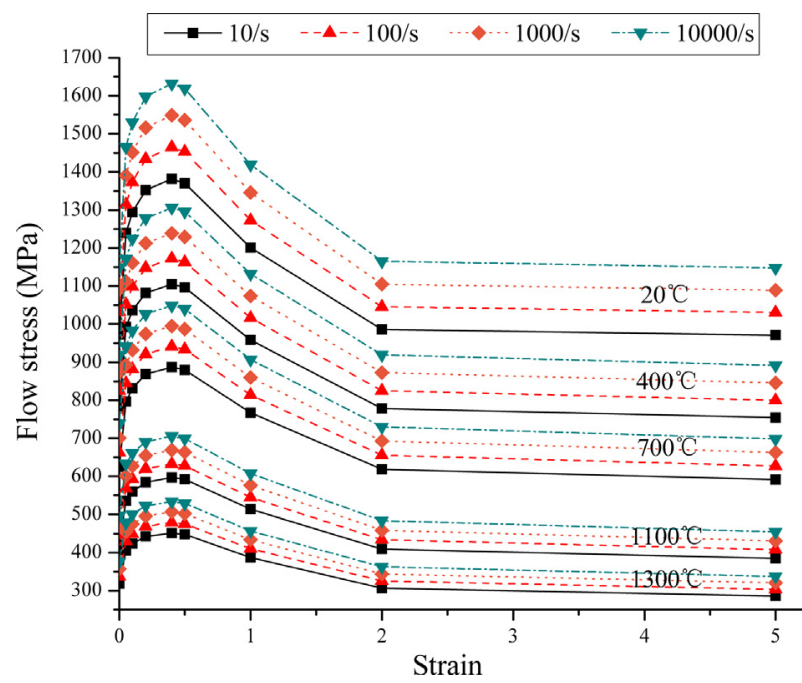

Fig.3. Flow stress curves of Calamaz J-C material model (Özel et al. [17]).

Table 3

Temperature-dependent material properties of Ti6Al4V alloy [17].

\begin{tabular}{ll}
\hline Properties & Ti6Al4V \\
\hline$E[\mathrm{MPa}]$ & $0.7412 \mathrm{~T}+113375$ \\
$\alpha\left[1{ }^{\circ} \mathrm{C}^{-1}\right]$ & $3 \times 10^{-9} \mathrm{~T}+7 \times 10^{-6}$ \\
$\lambda\left[\mathrm{Wm}^{-1}{ }^{\circ} \mathrm{C}^{-1}\right]$ & $7.039 \mathrm{e}^{0.0011 \mathrm{~T}}$ \\
$C_{p}\left[\mathrm{~N} \mathrm{~mm}{ }^{-2}{ }^{\circ} \mathrm{C}^{-1}\right]$ & $2.24 \mathrm{e}^{0.0007 \mathrm{~T}}$ \\
\hline
\end{tabular}

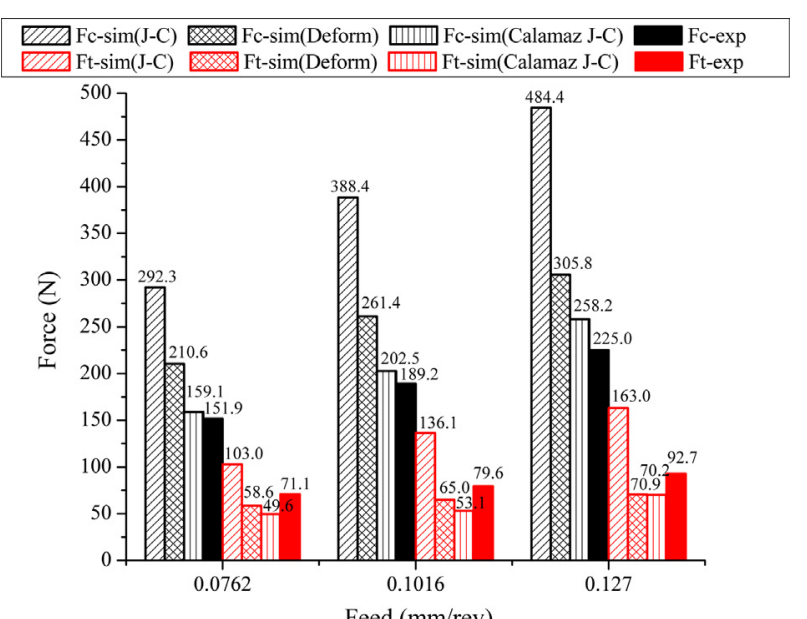

Fig. 4. Comparison of simulations and experimental data for cutting and thrust forces for various models.

Table 2

Parameters of Calamaz-modified Johnson-Cook material model for Ti6Al4V alloy.

\begin{tabular}{|c|c|c|c|c|c|c|c|c|c|c|}
\hline Calamaz J-C model & $A$ & $B$ & $n$ & C & $m$ & $a$ & $b$ & $d$ & $r$ & $s$ \\
\hline Özel et al. [17] & 782.7 & 498.4 & 0.28 & 0.028 & 1 & 2 & 5 & 1 & 2 & 0.05 \\
\hline
\end{tabular}


were $0^{\circ}$ and $11^{\circ}$, respectively. Three different feed rates 0.0762 , 0.1016 and $0.127 \mathrm{~mm} / \mathrm{rev}$ were used for each model. Orthogonal cutting of Ti6Al4V alloy with the same cutting parameters was implemented by Sima and Özel [16]. The cutting (Fc) and thrust $(\mathrm{Ft})$ forces calculated with three different material models and the respective experimental data are presented in Fig. 4. It should be mentioned that the depth of cut in simulations and experiments should be converted to the same value, because the orthogonal experiments performed on Ti6Al4V alloy tubes with wall thickness of $3.175 \mathrm{~mm}$.

Apparently, the cutting forces at three different feed rates obtained with the Calamaz J-C material model (Fig. 4) show the lowest deviations from the experimental results. Thus, the Calamaz $\mathrm{J}-\mathrm{C}$ model described the experimental results well; hence, it was integrated into the FE model of microstructural evolution.

\section{Numerical simulations of microstructural evolution}

A schematic of orthogonal cutting with ultrasonic vibration in the direction of the cutting velocity simulated below is shown in Fig. 5. The bottom side of the workpiece is provided with a kinematic boundary condition, while its top surface is free. The material is assumed to enter from the left-hand side of the workpiece and exit at its right-hand side and top surface.

The cutting tool (rake angle of $0^{\circ}$, relief angle of $7^{\circ}$ ) was assumed rigid and immovable in simulations of CC. However, vibration in the direction of cutting velocity was applied to the tool in the simulations of UAC. The vibration velocity was given by:

$v_{x}=2 \pi f A_{x} \sin (2 \pi f t), \quad v_{y}=0$,

where the frequency $f=20 \mathrm{kHz}$ and amplitude $A_{x}=20 \mu \mathrm{m}$. The maximum tool vibration speed $2 \pi f A(2513 \mathrm{~mm} / \mathrm{s})$ was larger than the cutting speed of $40 \mathrm{~m} / \mathrm{min}(666.7 \mathrm{~mm} / \mathrm{s})$; thus, the tool separated from the workpiece in each vibration cycle.

In order to analyse microstructural evolution in UAC, the JMAK was used. The main idea of this approach is to calculate a recrystallized volume fraction inside the material and use information on the initial grain size $d_{0}$ to model the microstructure. The FE software Deform-2D provided the model of grain growth, static, metadynamic and dynamic recrystallization as the function of strain, strain rate and temperature. In the cutting process, the dynamic recrystallization will take place. The volume fraction of dynamic recrystallization is defined with the Avrami equation as

$X_{D R x}=1-\exp \left[-\beta_{d}\left(\frac{\varepsilon-a_{10} \varepsilon_{p}}{\varepsilon_{0.5}}\right)^{k_{d}}\right]$,

where $\varepsilon$ is the strain, $\varepsilon_{p}$ is the peak strain, $\varepsilon_{0.5}$ is the strain level for $X_{D R x}=0.5$ and is defined as

$\varepsilon_{0.5}=a_{5} d_{0}^{h_{5}} \varepsilon^{n_{5}} \dot{\varepsilon}^{m_{5}} \exp \left(\frac{Q_{a c t} m_{5}}{R T}\right)+c_{5}$,

where $R$ is the universal gas constant. Dynamic recrystallization occurs when the critical strain $\varepsilon_{c}=a_{2} \varepsilon_{p}$ is reached, with the peak strain $\varepsilon_{p}$ given as

$\varepsilon_{p}=a_{1} d_{0}^{h_{1}} \dot{\varepsilon}^{m_{1}} \exp \left(\frac{Q_{a c t} m_{1}}{R T}\right)+c_{1}$.

The recrystallized grain size is defined as

$d_{D R x}=a_{8} d_{0}^{h_{8}} \varepsilon^{n_{8}} \dot{\varepsilon}^{m_{8}} \exp \left(\frac{Q_{a c t} m_{8}}{R T}\right)+c_{8}$.

The average grain size is calculated from the mixture as

$d_{a v g}=d_{0}\left(1-X_{D R x}\right)+d_{D R x} X_{D R x}$.

The JAMK model parameters $a_{1}, h_{1}, m_{1}, Q_{a c t}, c_{1}, a_{5}, h_{5}, n_{5}, m_{5}$, $c_{5}, a_{8}, h_{8}, n_{8}, m_{8}, c_{8}, \beta_{d}, a_{10}$ and $k_{d}$ for Ti6Al4V alloy (see Table 4) were provided by running sensitivity analysis with Deform-2D FE simulations [20]. The microstructure of Ti6Al4V alloy consists of two phases- $\alpha$ and $\beta . \alpha$ - grains have a typical average grain size of $d_{0}$, while $\beta$ - grains from the matrix containing net structures and are hard to assess. In Section 3, the average grain size was counted for $\alpha$ - grains; the as-received grain size was $d_{0}=20 \mu \mathrm{m}$, and phase transitions were not considered.

Employing this JMAK model in Deform-2D allowed assessment of microstructural evolution for the machined surface and the chip.

\subsection{Microstructural evolution of machined surface}

In the orthogonal UAC process, the cutting tool passes the machined surface back and forth. Thus, the magnitudes of strain, strain rate and temperature differ from those for CC. Five points under the machined surface were determined to track the states of each parameter. Apparently, parameters change more quickly

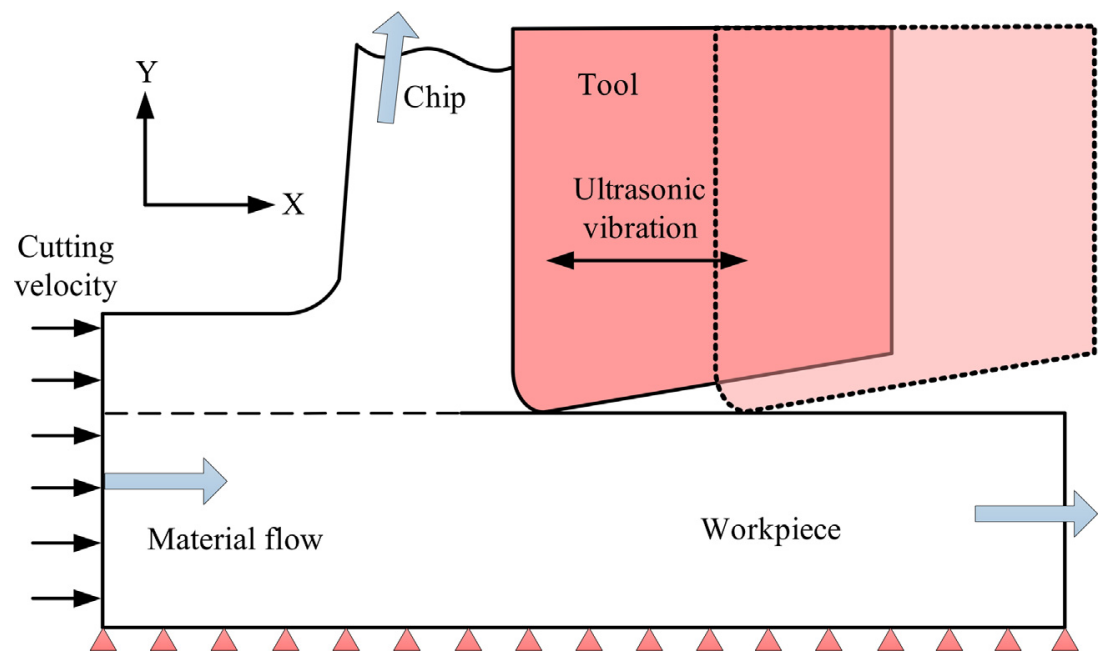

Fig. 5. Boundary conditions for orthogonal UAC. 
Table 4

JMAK model parameters for Ti6Al4V alloy [20].

\begin{tabular}{|c|c|c|c|c|c|c|c|c|c|}
\hline \multirow{2}{*}{$\begin{array}{l}\text { Ti6Al4V } \\
\text { Peak strain }\end{array}$} & \multicolumn{9}{|c|}{ JMAK model parameters } \\
\hline & $a_{1}$ & $\mathrm{~h}_{1}$ & $m_{1}$ & $Q_{a c t} m_{1}$ & $c_{1}$ & $a_{2}$ & & & \\
\hline & 2 & 0 & 0.006 & 1308 & 0 & 0.8 & & & \\
\hline \multirow[t]{2}{*}{ DRx kinetics } & $a_{5}$ & $\mathrm{~h}_{5}$ & $n_{5}$ & $m_{5}$ & $Q_{a c t} m_{5}$ & $c_{5}$ & $\beta_{d}$ & $k_{d}$ & $a_{10}$ \\
\hline & $1.21 \mathrm{e}-5$ & 0.13 & 0 & 0.04 & 8720 & 0 & 0.693 & 2 & 0 \\
\hline \multirow[t]{2}{*}{ DRx grain size } & $a_{8}$ & $\mathrm{~h}_{8}$ & $n_{8}$ & $m_{8}$ & $Q_{a c t} m_{8}$ & $c_{8}$ & & & \\
\hline & 150 & 0 & 0 & -0.03 & -6540 & 0 & & & \\
\hline
\end{tabular}

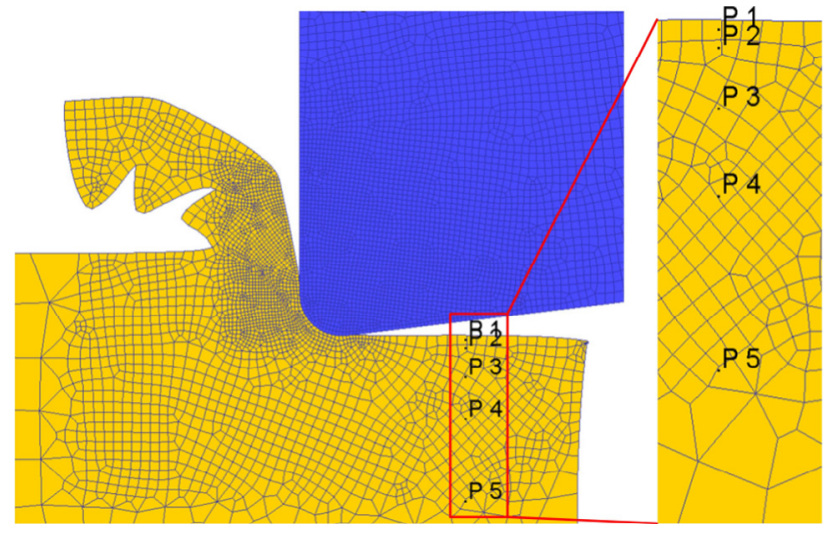

Fig. 6. Positions of five points under machined surface.

in areas close to the machined surface. So, the points were distributed unevenly in the depth: $0.005 \mathrm{~mm}, 0.015 \mathrm{~mm}, 0.050 \mathrm{~mm}$, $0.100 \mathrm{~mm}$ and $0.200 \mathrm{~mm}$, as shown in Fig. 6 .

The calculated magnitudes of strain, strain rate and temperature for the five points are shown in Fig. 7 for CC and UAC. The shaded zones represent the period that the tool passes above the points. The strain in UAC is somewhat larger than that in CC during the entire cutting duration as shown in Fig. 7(a) and (b). However, evolution of the strain rate is quite different (Fig. 7(c) and (d)): it fluctuates sharply as the tool is engaged with the workpiece in UAC, reaching considerably higher values than that in CC. In addition, temperature of the machined surface in CC and UAC has the similar trend, increasing dramatically as the tool passes and reducing slowly afterwards to a steady state; the maximum temperature in UAC is larger than that in CC.

It can be deduced from the JMAK model that the different characters of evolution of strain, strain rate and temperature should lead to different evolutions of microstructure in CC and UAC. As shown in Fig. 8(a) and (b), the recrystallized grain size for UAC is significantly different from that for CC. It is obviously smaller, and eventually tends towards zero. It is because the tool separates from the workpiece in each cutting cycle in UAC, thus, resulting in the rapid change of strain rate and temperature fluctuations. However, both the strain rate and temperature have a great impact on dynamic recrystallization and dynamic recovery. As a result, the recrystallization grain size cannot grow continuously due to the alternating dynamic recrystallization and recovery. In addition, the volume fraction of recrystallized grains has the same mechanism and the evolution trend. It can be concluded from Eq. (9) that the average grain size in a workpiece subjected to UAC is larger than that of CC as confirmed by Fig. 8(c) and (d). The average grain size of surface and subsurface in CC decreases dramatically when the tool passes. After this pass, the average grain size increases slowly due to the recovery, after which the grain size stabilizes. Eventually, the average grain size of the machined surface in UAC is larger than that in CC.
Besides, the recrystallized grain size reduces from P1 to P5 for both CC and UAC. On the contrary, the average grain size increases.

\subsection{Microstructural evolution in chip}

In order to investigate microstructural evolution in the chip, several points under the unmachined surface should be tracked. However, features of chip formation are not evident. So, thirty points under the unmachined surface were chosen, forming three columns with ten points each, distributed uniformly in columns. As shown in Fig. 9, thirty tracked points moved from the undeformed chip zone to the deformation zone. The upper points under the unmachined surface moved into the sawtooth zone, the middle points got into the primary shear zone, and the lower points moved into the secondary shear zone. In addition, it can be observed that the three columns have similar movement patterns; thus, only one column is enough to track the microstructural evolution. It should be mentioned that the simulated process shows the evolution of tracked points are similar in CC and UAC.

So, ten points under the unmachined surface were chosen for this purpose. The ten points were distributed uniformly as shown in Fig. 10.

The movement of tracked points and evolution of average grain size with chip formation by CC and UAC are investigated as shown in Fig. 11. It also can be obtained that the upper points in undeformed zone by both CC and UAC enter the sawtooth zone in deformation zone, the middle points move into the primary shear zone, and the lower points enter the secondary shear zone as shown in Fig. 12(a), (b), (d) and (e). Eventually, all the points get into the chip as shown in Fig. 12(c) and (f). Besides, Fig. 12(c) and (f) indicate that the average grain size of the chip in UAC is larger than that in CC. Because the colour changes from green to deep yellow by UAC and it changes from blue to green by CC. For accurate comparisons, the state variable evolutions of ten points are studied next.

The evolution of recrystallized and average grain sizes in the chip produced with CC and UAC is given in Fig. 12. The main trends of these processes are similar to those observed for the points under the machined surface (Fig. 8) still, the magnitudes of recrystallized and average grain sizes for UAC were quite different from those for CC. The dynamic recrystallization occurred when points moved into the deformation zone as seen in Fig. 12(a) and (b). It is also apparent that the recrystallization process developed discontinuously in UAC, since the tool and the chip separated periodically. As a result, the recrystallized grain size in UAC is smaller than that in CC. Finally, the average grain size in the chip in UAC was larger than that in CC (Fig. 12(c) and (d)). Interestingly, the final magnitudes of recrystallized and average grain sizes in CC and UAC for ten points did not increase or decrease consistently from P1 to P10. For instance, the middle points had the highest recrystallized grain size and the minimum average grain size; the reason for this was their movement into the shear band (this is validated in Section 4). 

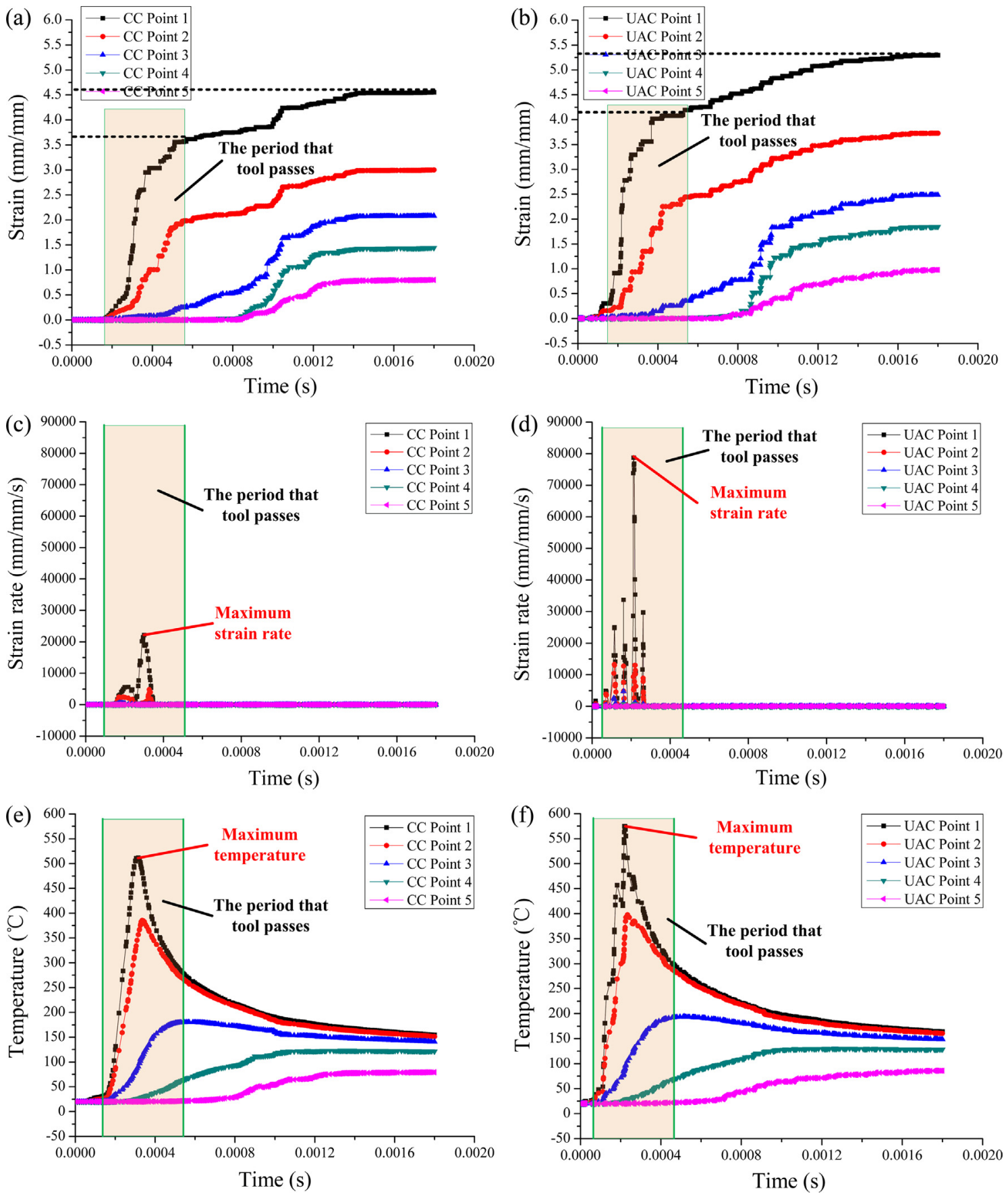

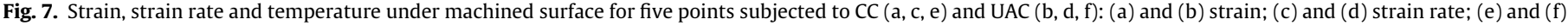
temperature.

\section{Experimental investigation}

To validate the numerical results for microstructural evolution in the machined surface and chip, tests with orthogonal CC and UAC were performed. As shown in Fig. 13, the ultrasonically assisted cutting device was fixed on the lathe, connecting the piezoelectric transducer and the concentrator. A cementedcarbide cutting tool was attached to the bottom of concentrator. The workpiece was machined with equidistant grooves, and the cutting edge was parallel to the cylindrical surface of the workpiece so that cutting process was performed in a $2 \mathrm{D}$ plane state, which was the same as in the numerical analysis. Fig. 13 also shows the sample preparation for observation and assessment of the microstructure specimens of the machined surface were obtained with wire-electrode cutting. After polishing and etching, microstructures of the machined surface and the chip were observed with the metallographic microscope.

This study used orthogonal CC and UAC regimes with a cutting speed at $20 \mathrm{~m} / \mathrm{min}$ and a feed rate at $0.1 \mathrm{~mm} / \mathrm{rev}$. In UAC, the vibration amplitude was $7.7 \mu \mathrm{m}$ with frequency of $20,220 \mathrm{~Hz}$. These parameters were also employed in numerical modelling for comparability in this Section, including the original grain size of $16.22 \mu \mathrm{m}$ that will be discussed below. Still, the numerical analysis with a cutting speed at $40 \mathrm{~m} / \mathrm{min}$, vibration amplitude of $20 \mu \mathrm{m}$ 

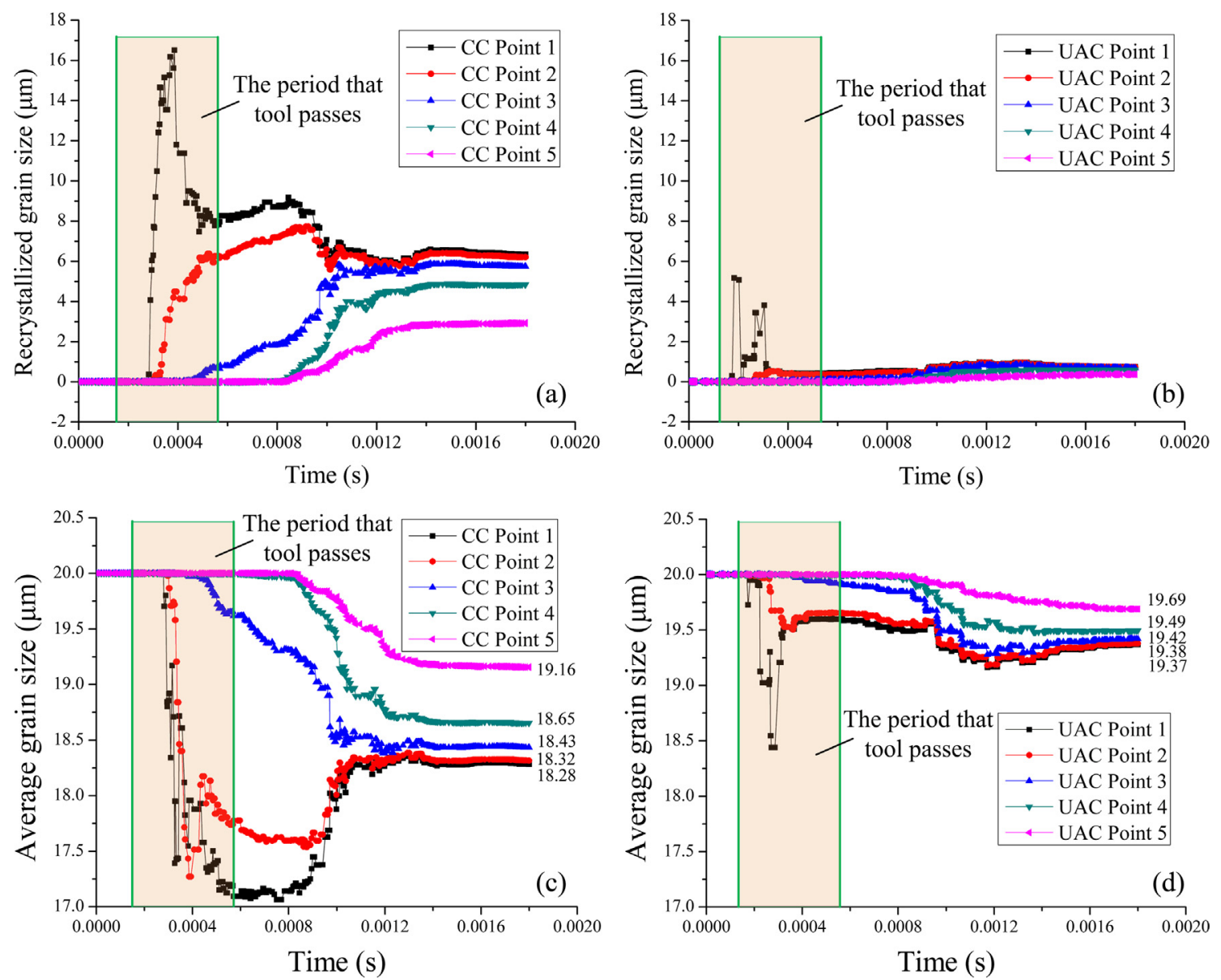

Fig. 8. Microstructure evolution under machined surface for CC (a and c) and UAC (b and d): (a) and (b) recrystallized grain size; (c) and (d) average grain size.

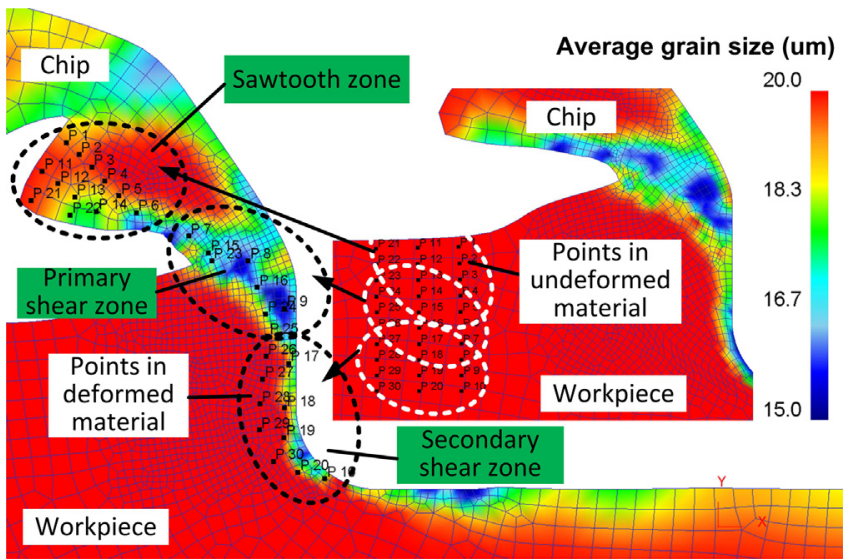

Fig. 9. Evolution of position of tracked points.

and the original grain size of $20 \mu \mathrm{m}$ in Section 3 was implemented to highlight the differences in the process of microstructural evolution in CC and UAC.

Prior to machining tests, several specimens obtained from the Ti6Al4V cylindrical workpiece were used to analyse the asreceived microstructure. Fig. 14 shows these microscopic images and a grain-size distribution. The microstructure of Ti6Al4V alloy consists of two phases: $\alpha$ and $\beta . \alpha$ - grains had a typical equiaxed structure, while $\beta$ - grains formed the matrix. The average grain diameter of cylindrical billet was found to be $16.22 \mu \mathrm{m}$ as shown in Fig. 14.

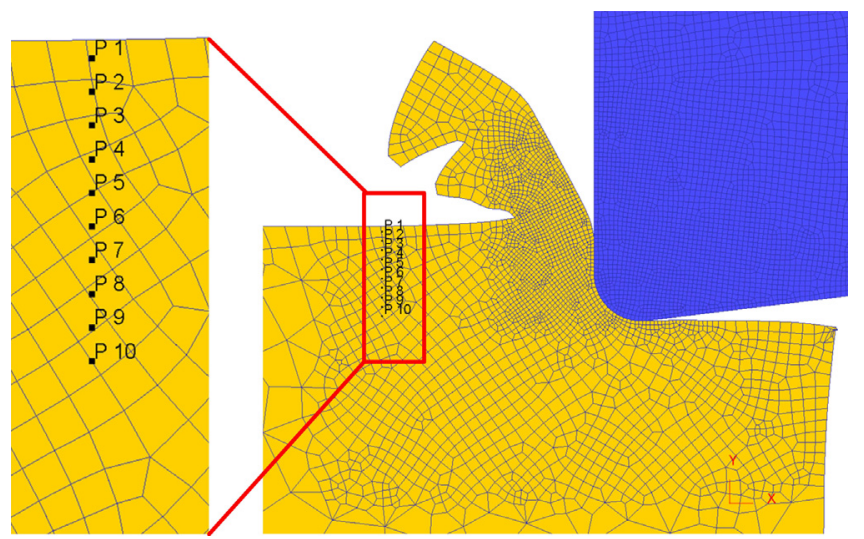

Fig. 10. Distribution of ten points under unmachined surface.

Additionally, microhardness measurements were taken using nanoindentation to further verify the distribution of microstructure as shown in Fig. 15. This allowed the indentations at much a smaller scale that is important for analysis of the chip.

\subsection{Experiments on workpieces}

The microstructures obtained for areas under the machined surface are illustrated in Fig. 16; for this study, five points corresponding to respective locations studied in the FE simulations under the 


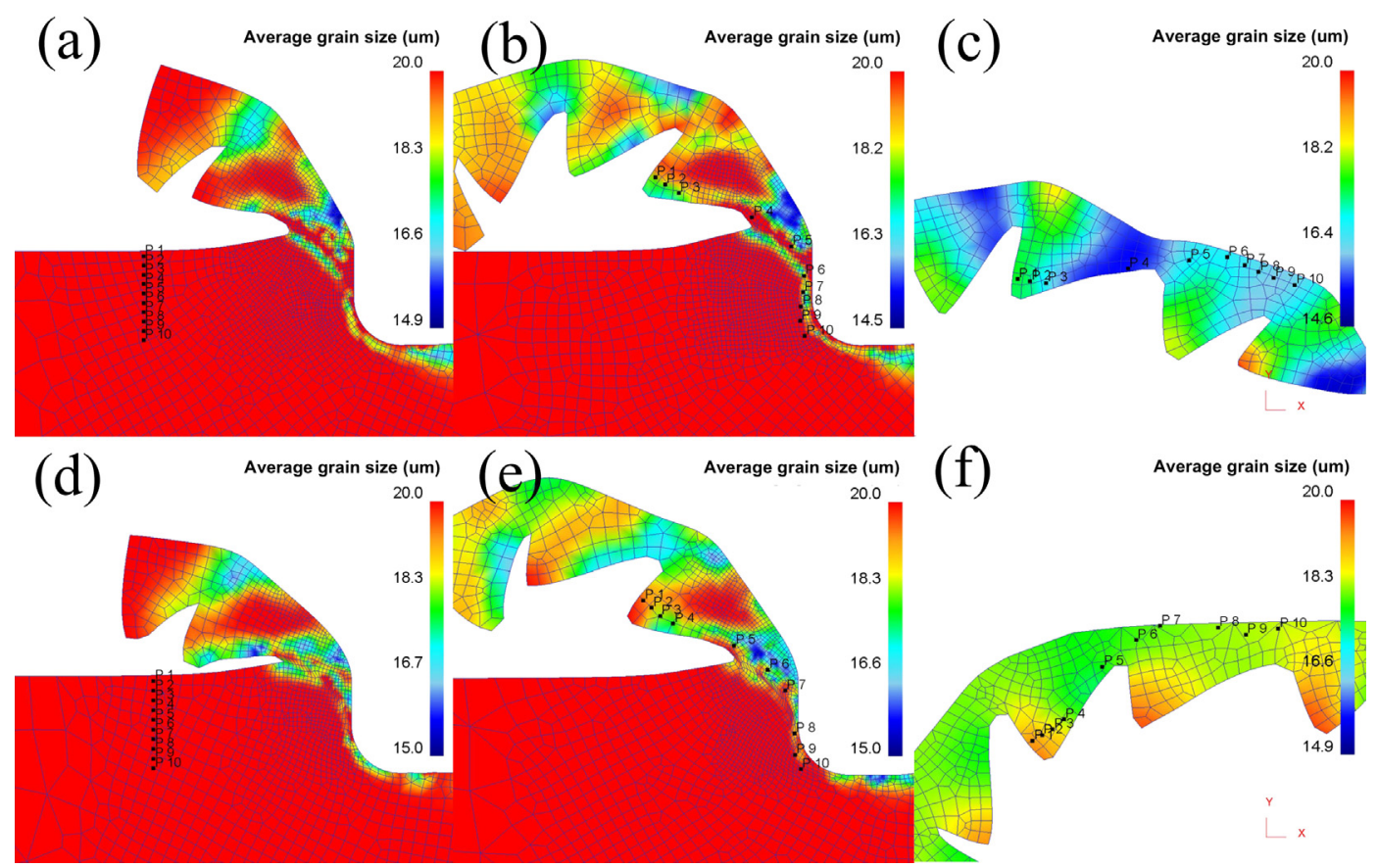

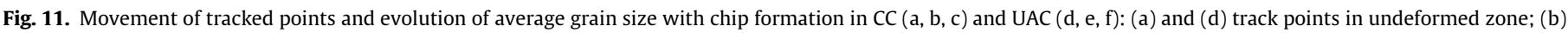
and (e) track points in deformation zone; (c) and (f) track points in chip.

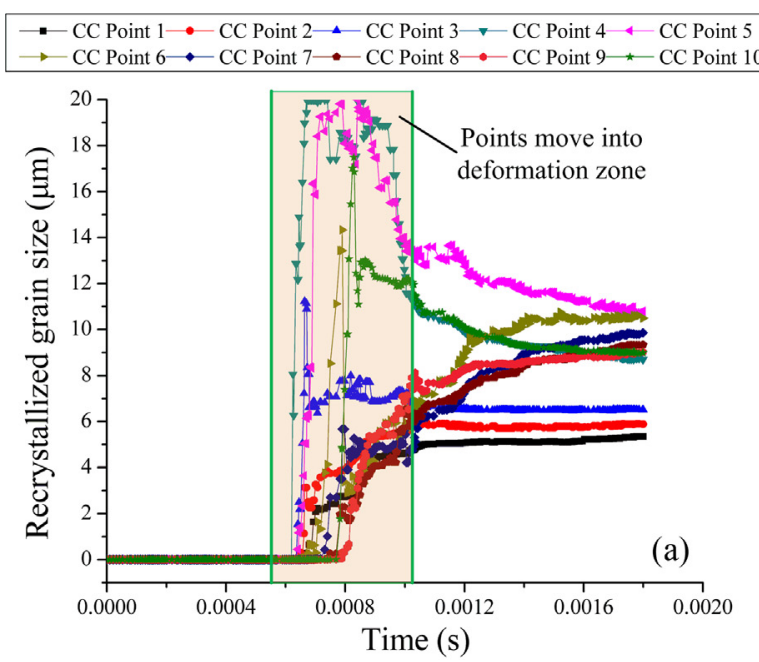

$\because$ CC Point $1-$ CC Point $2-$ CC Point $3-$ CC Point $4 \longleftarrow$ CC Point 5 $\rightarrow$ CC Point $6-$ CC Point $7-$ CC Point $8-$ CC Point 9 * CC Point 10

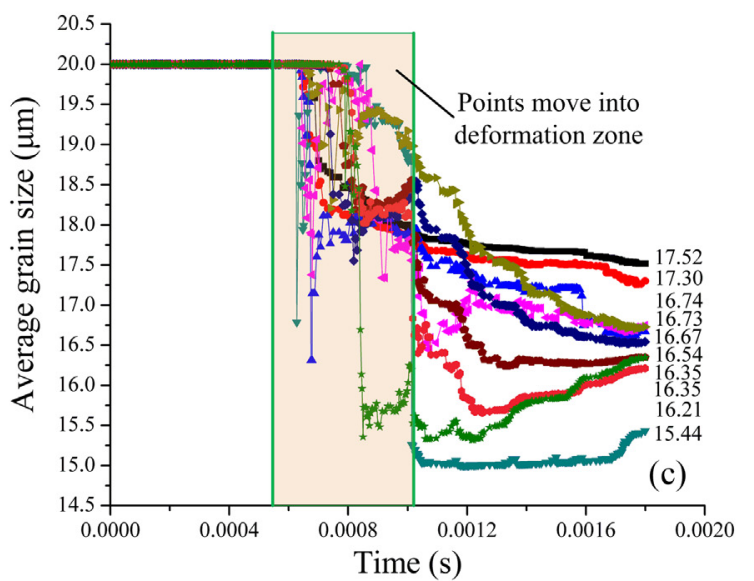

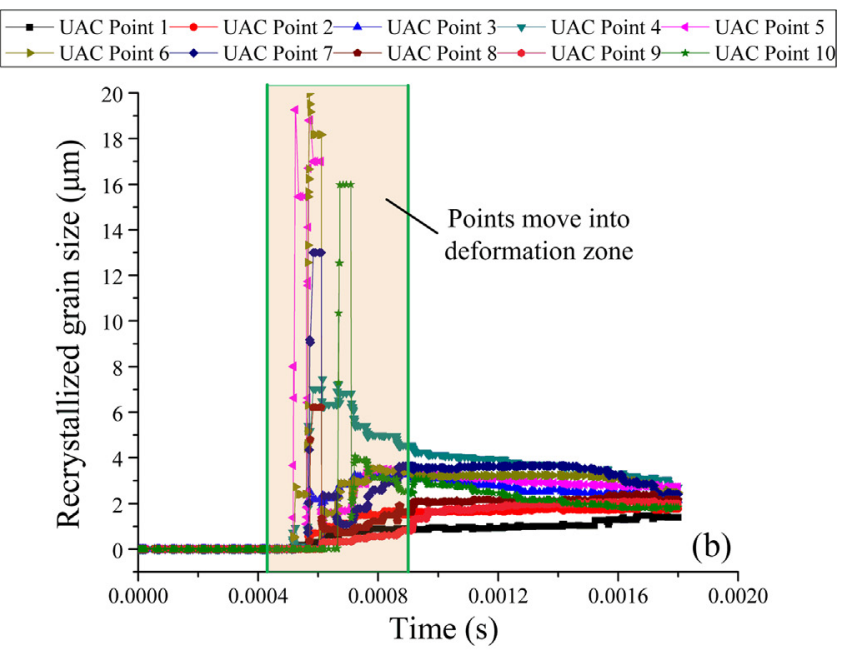

$\because$ UAC Point $1-$ UAC Point $2-$ UAC Point $3 \multimap$ UAC Point $4 \longleftarrow$ UAC Point 5 UAC Point 6 - UAC Point 7 - UAC Point 8 - UAC Point 9 * UAC Point 10

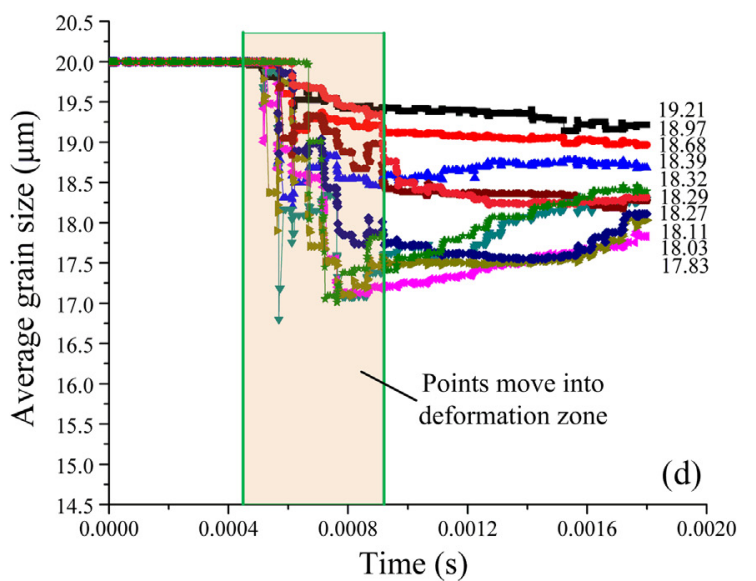

Fig. 12. Microstructure evolution in chip produced with CC (a and c) and UAC (b and d): (a) and (b) recrystallized grain size; (c) and (d) average grain size. 


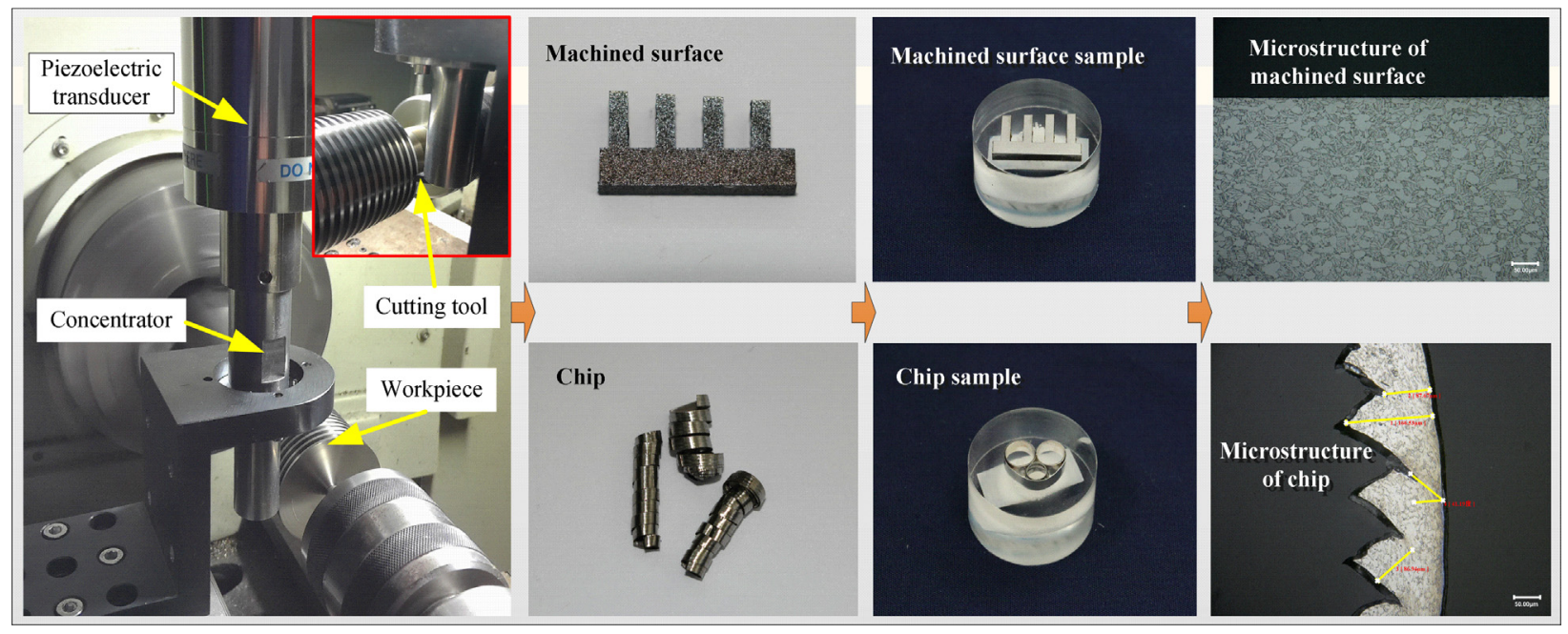

Fig. 13. Experimental setup and sample preparation.

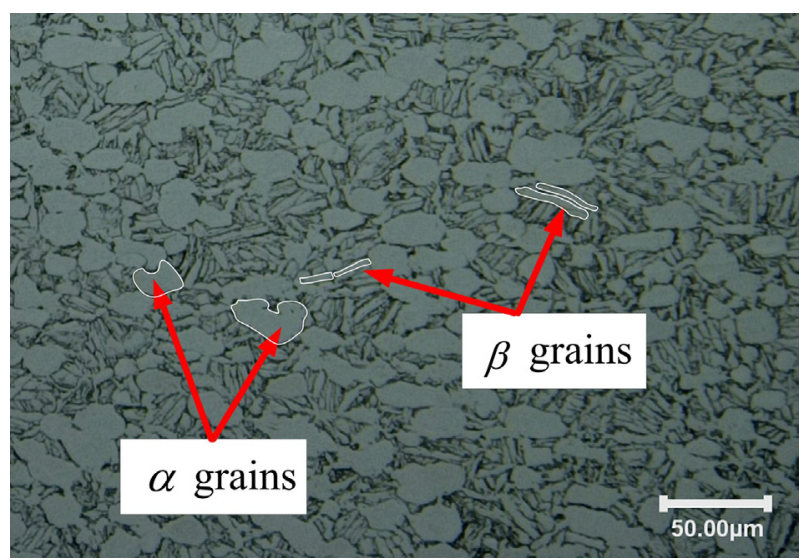

Fig. 14. As-received microstructure of Ti6Al4V.

machined surface were marked and the average grain size was measured using a linear intercept method.

The measurements show that the grain size changes significantly: under the surface machined with $\mathrm{CC}$ it was in the range from $5.72 \mu \mathrm{m}$ to $27.63 \mu \mathrm{m}$, while for UAC - from $5.70 \mu \mathrm{m}$ to $30.26 \mu \mathrm{m}$. The histograms of distribution of grain size under the machined surface for CC and UAC were obtained (Fig. 17); the statistical results show that most grain sizes in CC were dispersed in the range from $8.45 \mu \mathrm{m}$ to $22.25 \mu \mathrm{m}$. In contrast, a significant part of grain sizes in UAC were in the range to the initial grain size $d_{0}=16.22 \mu \mathrm{m}$.

The obtained numerical and experimental results for the average grain size for five different depths under the machined surface are compared for CC and UAC in Fig. 18. It demonstrates that the predicted and measured average grain sizes are very close. Generally, the average grain size in UAC is larger than that in CC, and is more close to $d_{0}$. In addition, the main trend for the average grain size increased from P1 to P5.

In order to further validate the distribution of grain size under the machined surface for the two studied cutting techniques, microhardness of the machined surfaces was tested with a nanoindenter. Many researchers investigated a relationship between hardness and the grain size $[8,21]$; according to those results, hard-

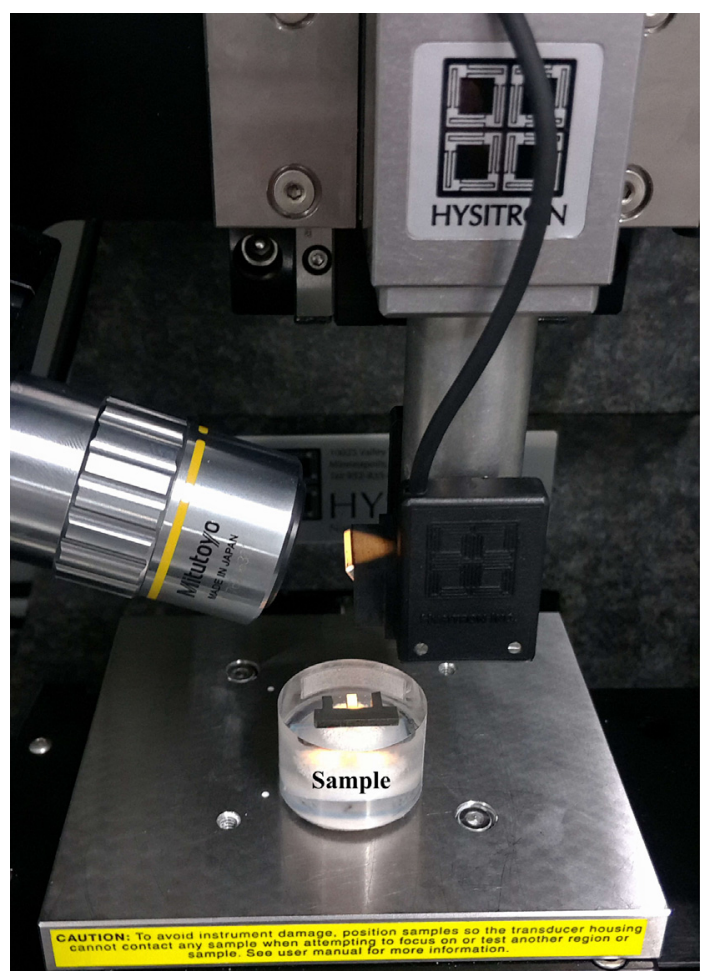

Fig. 15. Microhardness measurement with nanoindenter.

ness decreases with the increasing grain size. Indeed, the average grain size and microhardness respond differently to strain, strain rate and temperature. A zone with severe plastic deformation stores more deformation energy, causing more intensive dynamic recrystallization. Thus, the average grain size in such a zone is smaller, and it has more energy to resist the indentation deformation. Hence, the zone with a smaller grain size has higher microhardness.

The microhardness tests of the workpieces under the machined surfaces were performed, with their results as shown in Fig. 19. Generally, both CC and UAC demonstrated the same trend: the level of microhardness decreased with the depth. This decrease was rapid in CC and slow in UAC. Besides, microhardness near to 

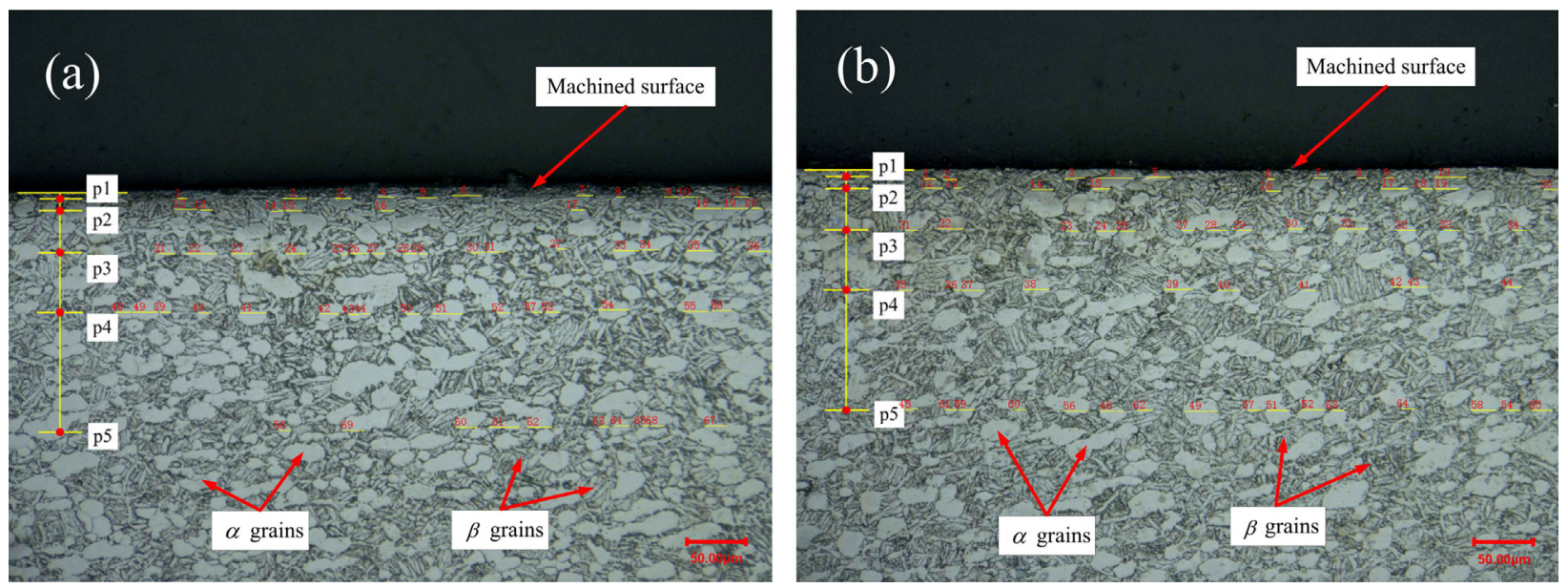

Fig. 16. Microstructure under machined surface: (a) CC; (b) UAC.
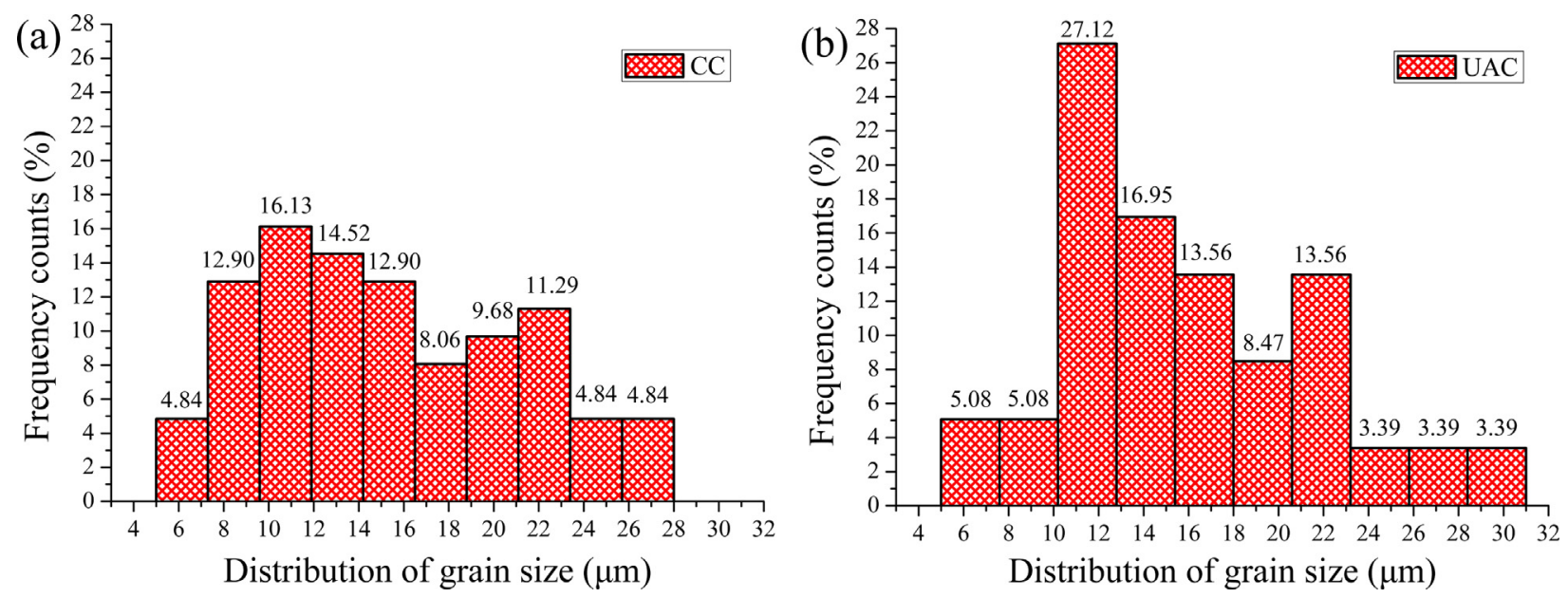

Fig. 17. Frequency counts of distribution of grain size under machined surface: (a) CC; (b) UAC.

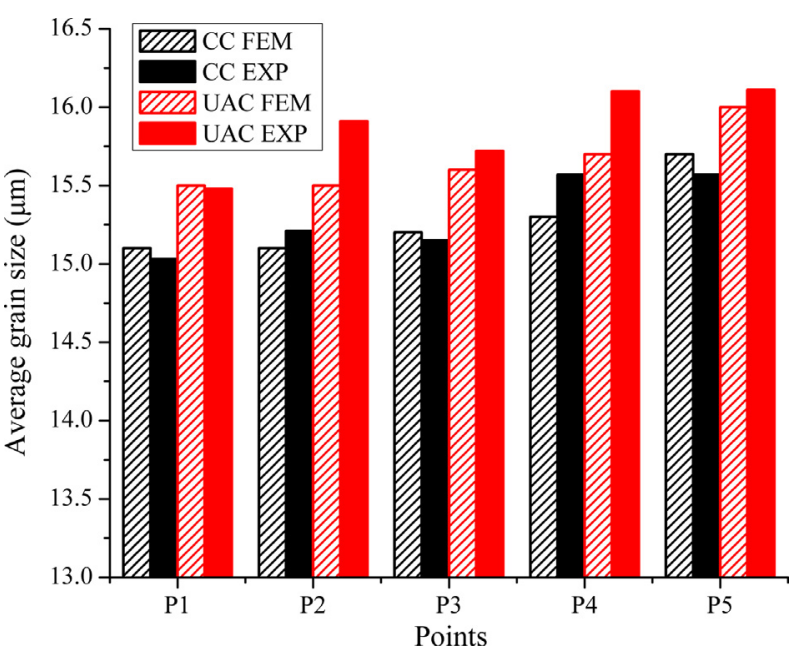

Fig. 18. Comparisons of numerical and experimental results for average grain size under machined surface in CC and UAC.

the machined surface was higher in CC than that in UAC. Thus, the microhardness study also confirmed the predicted microstructural changes in the workpieces machined with CC and UAC.

\subsection{Experiments on chips}

As mentioned in Section 3.2, the average grain size predicted for ten points in the chip decreased or increased nonlinearly, and the distribution was complex. Thus, the validation of the calculated average grain size of ten points is intractable. So, another solution was found: a number of points between two sawteeth in the chip were chosen to assess the distribution of the average grain size. The track points between the two sawteeth were placed with the same spacing, with the line crossing the shear band. Fig. 20 shows the predicted distribution of average grain size between two sawteeth in the chip obtained with the numerical model. Apparently, the average grain size decreased from P1 to the middle point, located in the shear band, followed by an increase to P24 in both CC and UAC. However, the minimum average grain size in UAC was larger than that in $\mathrm{CC}$, and the range of the average grain size in UAC was smaller than that in CC; it means that average grain size was more uniform in UAC.

Still, validation of the average grain size in the chip is quite complicated because it is hard to measure the grain size in the chip at the small scale. So, in this study only the microhardness tests were conducted; Fig. 21 shows the indentations in the segmented chip. The zone of indentations is marked with red rectangles, with 24 indentations distributed on a line crossing the shear band. 

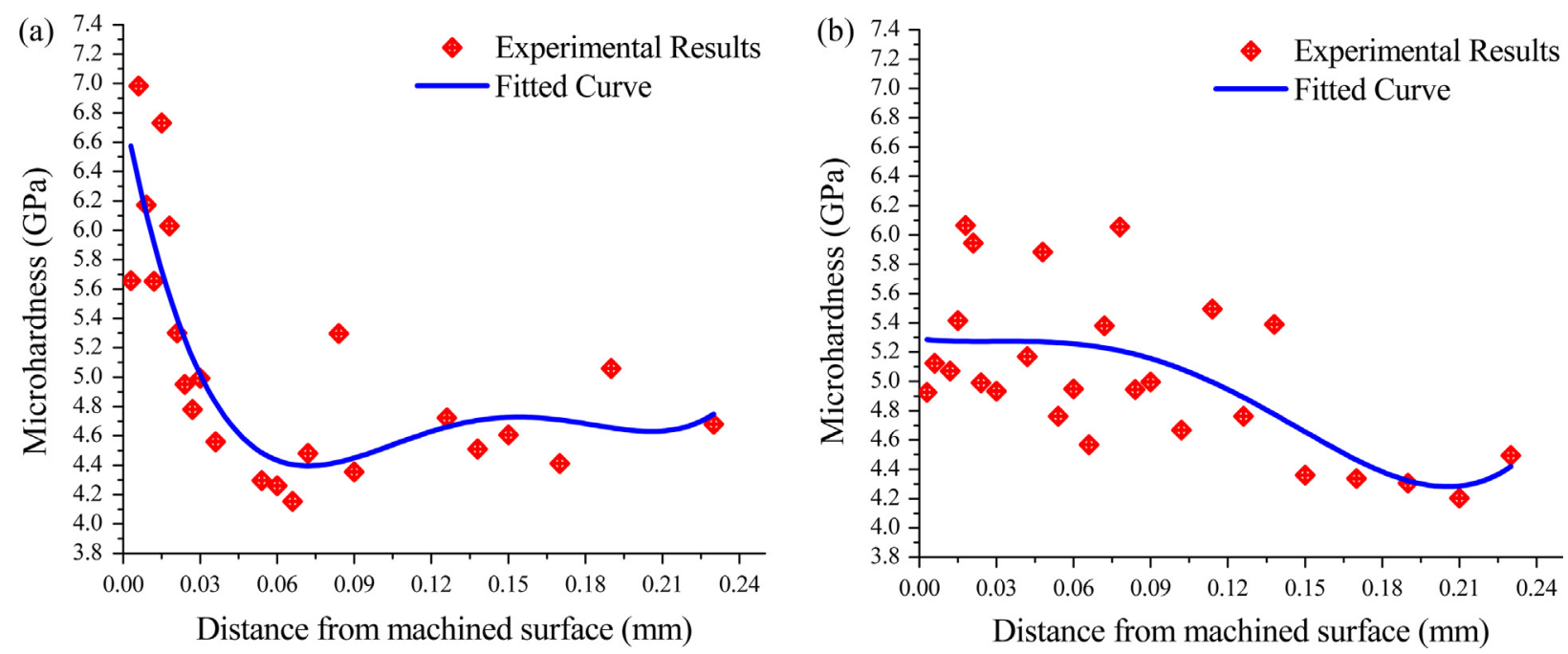

Fig. 19. Microhardness under machined surface: (a) CC; (b) UAC.
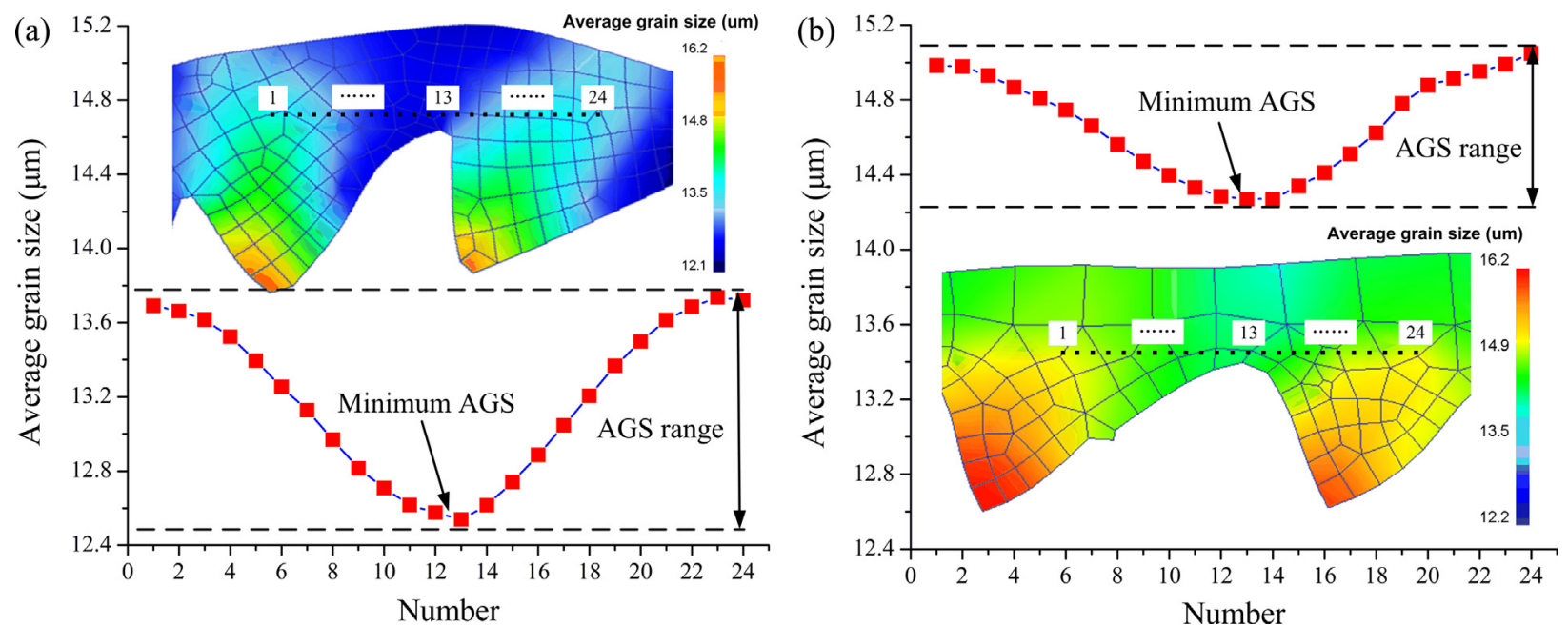

Fig. 20. Calculated distributions of average grain size (AGS) between two sawteeth in chip: (a) CC; (b) UAC.

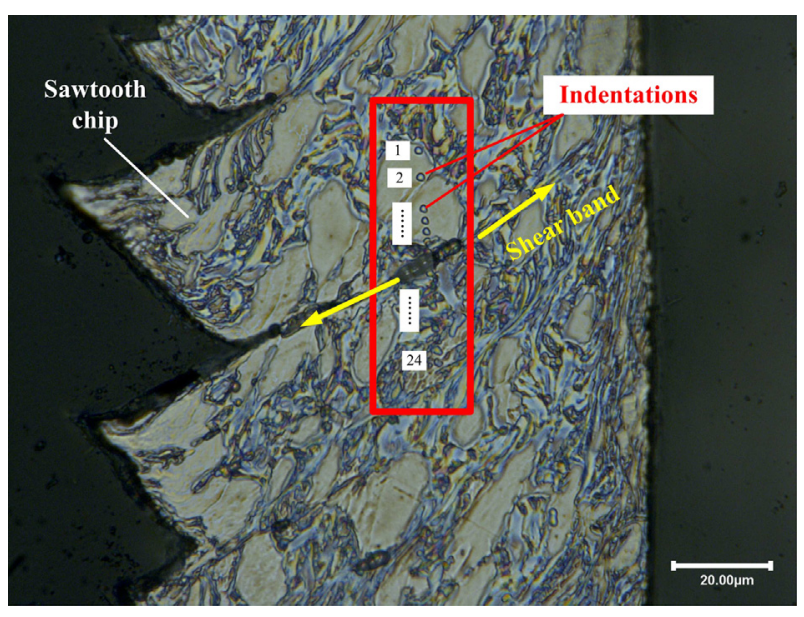

Fig. 21. Indentations in segmented chip.

Results of the microhardness tests in the chips produced with CC and UAC are presented in Fig. 22. The distribution of microhardness in the chips has the same trend for both CC and UAC that is an inverse of the predicted distributions for the average grain size. The maximum microhardness in shear band in UAC was lower than that in CC. Moreover, the range of microhardness in UAC is smaller than that in CC. These results indicate that the microhardness in segmented chips produced with UAC is smaller and distributed more uniformly, which, in turn, validates the distribution of the average grain size.

\section{Discussions}

In order to reveal the influence of cutting and vibration parameters on microstructure subjected to CC and UAC, an additional series of simulations was performed. The numerical simulations were implemented with the cutting speed of $20,40,60 \mathrm{~m} / \mathrm{min}$ and feed rate of $0.08,0.10,0.12 \mathrm{~mm} / \mathrm{rev}$, vibration amplitude of 10,15 , $20 \mu \mathrm{m}$ and original grain size of $20 \mu \mathrm{m}$ as in Section 3. Fig. 23 summarizes the results in term of the average grain size for the selected five points under the machined surfaces at different magnitudes of vibration amplitude, feed rate and cutting speed.

As shown in Fig. 23, the average grain size in UAC is larger than that in CC at different amplitudes and cutting parameters. Generally, the effects of vibration amplitude, feed and cutting speed on 

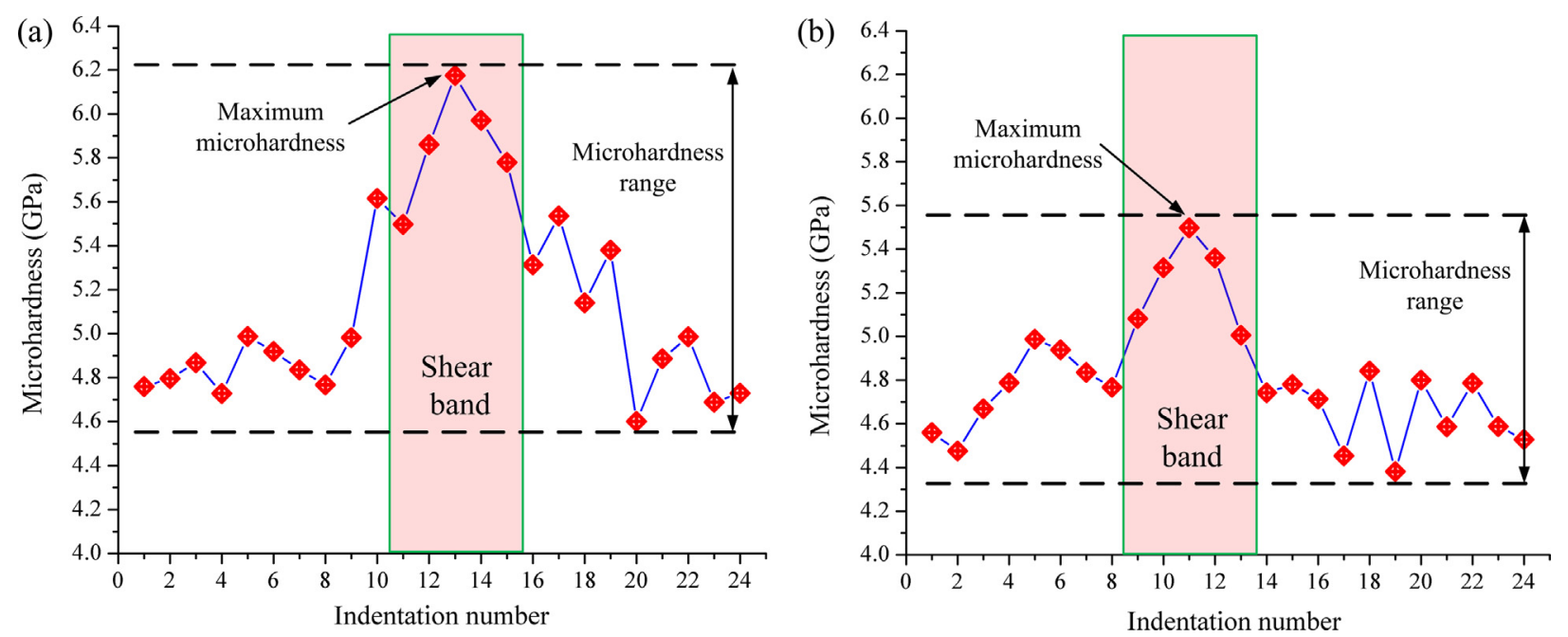

Fig. 22. Microhardness distribution in chip: (a) CC; (b) UAC.

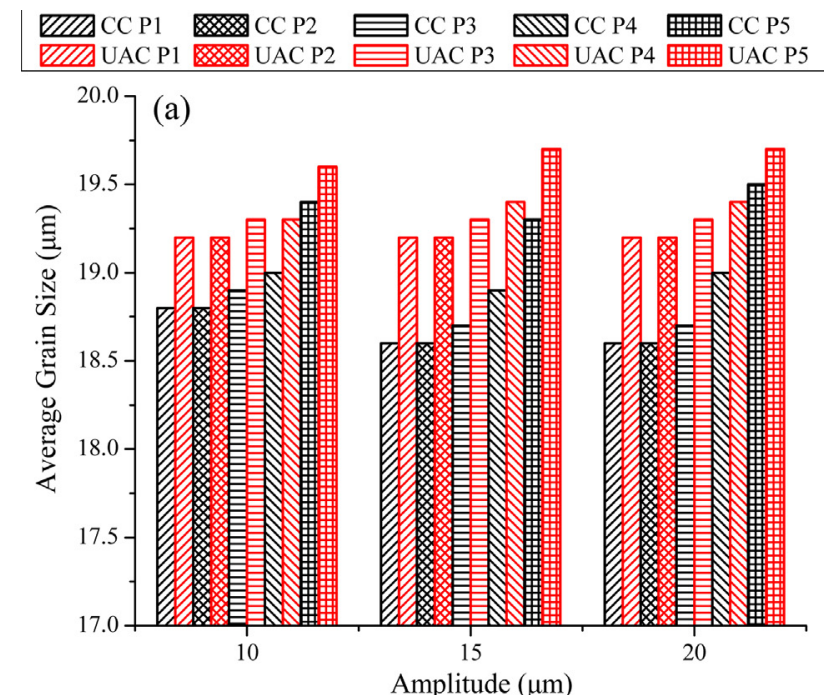

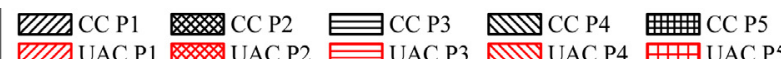
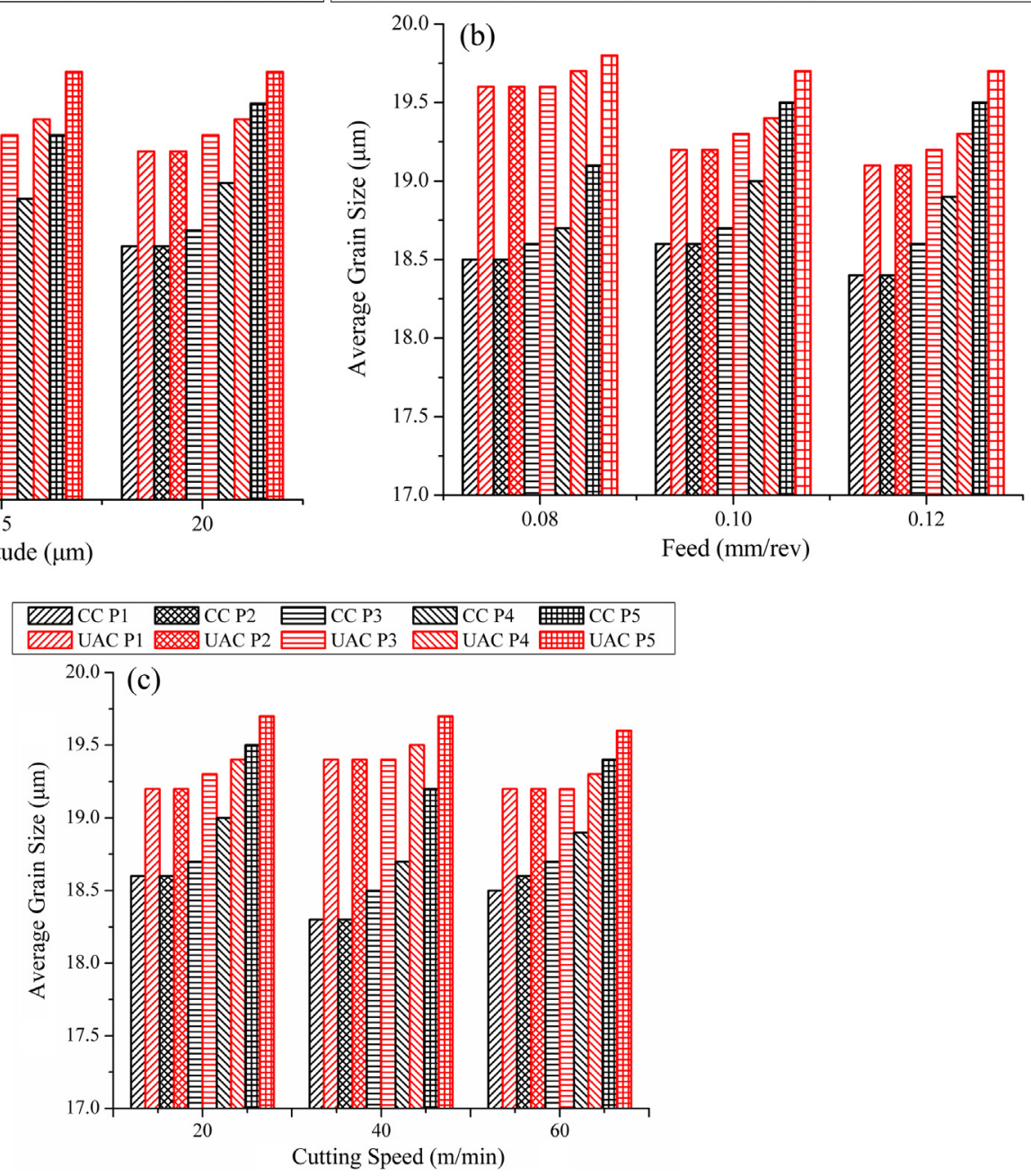

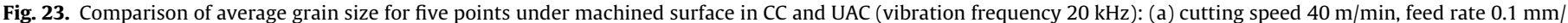
rev; (b) cutting speed $40 \mathrm{~m} / \mathrm{min}$, amplitude $20 \mu \mathrm{m}$; (c) amplitude $20 \mu \mathrm{m}$, feed rate $0.1 \mathrm{~mm} / \mathrm{rev}$. 
average grain size are not apparent. It was found that the difference between five points in UAC was smaller than that in CC. Thus, the comparisons show the UAC can achieve less intrusive processing.

\section{Conclusions}

In this paper, the numerical model for microstructural changes in the machined surface and subsurface as well as in the chip of Ti6Al4V alloy machined with UAC was developed and used. The distribution of average grain size in the machined surface and the chip was predicted. In addition, experiments with orthogonal cutting in the CC and UAC regimes were performed to validate the prediction of numerical modelling. Conclusions from this study can be drawn as follows:

(1) The Calamaz J-C material model showed the flow softening at high strains and high temperatures, which was more relevant than the J-C material model. Besides, by considering the temperature-dependent material properties and fracture criterion, the Calamaz J-C material model predicted the cutting process well. Our results demonstrated that the cutting and thrust forces calculated with the Calamaz J-C material model showed the lowest deviations from the experimental results than other two models.

(2) The JMAK model was used to analyse microstructural changes in UAC. Five points were distributed unevenly in the depth of the workpiece material below the machined surface to track the microstructural evolution in CC and UAC. The recrystallized grain size for UAC was significantly different from that for CC; it was apparently smaller and tended towards zero after the cutting tool passed. Eventually, the average grain size of the machined surface in UAC was larger than that in CC. Besides, the recrystallized grain size reduced with distance from the surface for both CC and UAC. On the contrary, the average grain size increased. For the chip, ten points under the unmachined surface were chosen to track. The main trends of recrystallized and average grain sizes were similar to those observed for the points under the machined surface. But due to chip segmentation in Ti6Al4V, the final magnitudes of recrystallized and average grain sizes in CC and UAC for ten points did not increase or decrease consistently.

(3) For the machined surface, experiments with orthogonal cutting demonstrated that the average grain size in UAC was larger than that in CC, and was more close to the initial grain size. In addition, the main trend for the average grain size from P1 to P5 was an increase. For the chip between two sawteeth, the minimum average grain size appeared in shear bands for both CC and UAC. However, the minimum average grain size in UAC was larger than that in $\mathrm{CC}$, and the range of the average grain size in UAC was smaller than that in CC; it means that the average grain size was more uniform in the former.

(4) An additional series of simulations showed that cutting and vibration parameters had no apparent effects on the distribution of the average grain size in CC and UAC. However, numerical modelling and experimental analysis both indicated that the average grain size in UAC was larger and more uniform, while the change of the average grain size in both locations for UAC was smaller than that for CC, thus showing that the UAC is a less damaging processing technique.

Our future work will focus on analysis of evolution of dislocation density and residual stresses under machined surface and in the chip in UAC.

\section{Acknowledgment}

This work was supported by the National Basic Research Program of China (973 Program) grant No. 2013CB035805.

\section{References}

[1] D.E. Brehl, T.A. Dow, Review of vibration-assisted machining, Precis. Eng. 32 (2008) 153-172.

[2] A. Maurotto, R. Muhammad, A. Roy, V.V. Silberschmidt, Enhanced ultrasonically assisted turning of a beta-titanium alloy, Ultrasonics 53 (2013) $1242-1250$.

[3] V.I. Babitsky, A.V. Mitrofanov, V.V. Silberschmidt, Ultrasonically assisted turning of aviation materials: simulations and experimental study, Ultrasonics 42 (2004) 81-86.

[4] R. Shivpuri, J. Hua, P. Mittal, A.K. Srivastava, G.D. Lahoti, Microstructuremechanics interactions in modeling chip segmentation during titanium machining, CIRP Ann. - Manuf. Technol. 51 (2002) 71-74.

[5] A. Simoneau, E. Ng, M.A. Elbestawi, Grain size and orientation effects when microcutting AISI 1045 steel, CIRP Ann. - Manuf. Technol. 56 (1045) (2007) 57-60.

[6] M. Abouridouane, F. Klocke, D. Lung, O. Adams, A new 3D multiphase FE model for micro cutting ferritic-pearlitic carbon steels, CIRP Ann. - Manuf. Technol. 61 (2012) 71-74.

[7] Z. Pu, D. Umbrello, O.W. Dillon, T. Lu, D.A. Puleo, I.S. Jawahir, Finite element modeling of microstructural changes in dry and cryogenic machining of AZ31B magnesium alloy, J. Manuf. Process. 16 (2014) 335-343.

[8] G. Rotella, O.W. Dillon, D. Umbrello, L. Settineri, I.S. Jawahir, Finite element modeling of microstructural changes in turning of AA7075-T651 Alloy, J. Manuf. Process. 15 (2013) 87-95.

[9] K. Moussaoui, M. Mousseigne, J. Senatore, R. Chieragatti, F. Monies, Influence of milling on surface integrity of Ti6Al4V-study of the metallurgical characteristics: microstructure and microhardness, Int. J. Adv. Manuf. Technol. 67 (2012) 1477-1489.

[10] Z.C. Sun, H. Yang, G.J. Han, X.G. Fan, A numerical model based on internalstate-variable method for the microstructure evolution during hot-working process of TA15 titanium alloy, Mater. Sci. Eng. A 527 (2010) 3464-3471.

[11] Y.P. Yi, X. Fu, J.D. Cui, H. Chen, Prediction of grain size for large-sized aluminium alloy 7050 forging during hot forming, J. Cent. South Univ. T. 15 (2008) $1-5$.

[12] W.S. Lee, C.F. Lin, Plastic deformation and fracture behaviour of Ti-6Al-4V alloy loaded with high strain rate under various temperatures, Mater. Sci. Eng. A 241 (1998) 48-59.

[13] P.F. Bariani, G. Berti, S. Corazza, Enhancing performances of SHPB for determination of flow curves, CIRP Ann. - Manuf. Technol. 50 (2001) 153-156.

[14] J. Sun, Y.B. Guo, Material flow stress and failure in multiscale machining titanium alloy Ti-6Al-4V, Int. J. Adv. Manuf. Technol. 41 (2008) 651-659.

[15] M. Calamaz, D. Coupard, F. Girot, A new material model for 2D numerical simulation of serrated chip formation when machining titanium alloy Ti-6Al4V, Int. J. Mach. Tools Manuf. 48 (2008) 275-288.

[16] M. Sima, T. Özel, Modified material constitutive models for serrated chip formation simulations and experimental validation in machining of titanium alloy Ti-6Al-4V, Int. J. Mach. Tools Manuf. 50 (2010) 943-960.

[17] T. Özel, M. Sima, A.K. Srivastava, B. Kaftanoglu, Investigations on the effects of multi-layered coated inserts in machining Ti-6Al-4V alloy with experiments and finite element simulations, CIRP Ann. - Manuf. Technol. 59 (2010) 77-82.

[18] M.G. Cockcroft, D.J. Latham, Ductility and the workability of metals, J. Inst. Met. 96 (1968) 33-39.

[19] D. Umbrello, Finite element simulation of conventional and high speed machining of Ti6Al4V alloy, J. Mater. Process. Technol. 196 (2008) 79-87.

[20] Y.M. Arısoy, T. Özel, Prediction of machining induced microstructure in Ti6Al-4V alloy using 3-D FE-based simulations: effects of tool micro-geometry, coating and cutting conditions, J. Mater. Process. Technol. 220 (2015) 1-26.

[21] Y.W. Sui, B.S. Li, A.H. Liu, H. Nan, J.J. Guo, H.Z. Fu, Microstructures and hardness of Ti-6Al-4V alloy staging castings under centrifugal field, T. Nonferr. Metal. Soc. 18 (2008) 291-296. 